\title{
Molecular Identification of a Novel Iflavirus in Brown-Spotted Pitvipers (Protobothrops Mucrosquamatus)
}

Zhige Tian

Yibin University

Ying Deng

Yibin University

Hongzhi Cao

Modern Agricultural College, Yibin Vocational and Technical College

Miaomiao Zheng

Yibin University

Ke Li

Yibin University

Yan Li

Sichuan Animal Sciences Academy

Furong Jiang

Yibin University

Ting Tang

Yibin University

Min Yu

Yibin University

Anting Zhang

Yibin University

Xue Xia

Yibin University

Peng Guo

Yibin University

Xiaoliang Hu ( $\sim$ liang679@163.com)

Yibin University

\section{Research Article}

Keywords: iflavirus, brown-spotted pitvipers, insects, genetic characterization

Posted Date: July 15th, 2021

DOI: https://doi.org/10.21203/rs.3.rs-701945/v1

License: @ (i) This work is licensed under a Creative Commons Attribution 4.0 International License. Read Full License 


\begin{abstract}
Background: Iflaviridae is a family of small non-enveloped viruses with monopartite, positive-stranded RNA genomes, which are identified in arthropod hosts, primarily infecting insect species. Herein, we firstly identify the sequence of an iflavirus (YB-PMP20) found in brown-spotted pitvipers in China.

Results: The sequence of YB-PMP20 showed high identity to the sequences of Hubei picorna-like virus (HUPV) (99.2\% in nt), Vespa velutina-associated iflavirus like virus (VVAIV) (58.6\% in nt) and Lygus lineolaris virus (LyIV-1) (46.6\% in nt) in nucleotides encoding polyproteins. It contained a single large ORF (304-9291 nt) encoding 2996 amino acids. The deduced amino acid sequences were compared with those of iflavirus. Helicase, protease and the RdRp domain were found to be located at the $3^{\prime}$ end, and structural genes (VP1, VP2 and VP3) were found to be located at the $5^{\prime}$ end. Phylogenetic analysis indicated that YB-PMP20 belongs to the iflavirus cluster, and is similar to HUPV, LyIV-1 and VVAIV.
\end{abstract}

Conclusion: The present study described the genetic characterization of a PmIFV strain in brown-spotted pitvipers. Our genomic data extend knowledge of the diversity of viruses in snakes.

\title{
1. Introduction
}

Iflavirus is a member of the family Iflaviridae, order Picornavirales, which has a positive-stranded RNA genome between 9 and 11 kilobases in length [1]. The iflavirus genome organization is monopartite and monocistronic, encoding capsid proteins at the $5^{\prime}$ end and replicase proteins at the $3^{\prime}$ end [2]. All classified iflavirus species infect arthropod hosts, mostly insects, including the honey bee [3], planthopper [4], soybean thrip [5], Varroa destructor [6], aedes mosquito [7, 8], sogatella furcifera [9] and leafhopper [10].

Many viruses have been described in diverse snake species, for example, ranavirus (Chondropython viridis) [11], erythrocytic necrosis virus (Thamnophis sauritus) [12], herpesvirus (Boa constrictor) [13], adenovirus (Python regius) (Pantherophis guttatus) [14, 15], parvovirus (Pantherophis guttatus) [16], circovirus (Aspidites melanocephalus) [17], retrovirus (Vipera russelli) [18], reovirus (Python regius) [19], paramyxovirus (Bothrops alternatus) [20-22], calicivirus (Crotalus unicolor) [23], Japanese encephalitis virus (Zaocys dhumnades) [24], Western equine encephalitis virus (Thamnophis) [25] and picornavirus (Zamenis lineata) [26].

The present study first investigated the brown-spotted pitviper (Protobothrops mucrosquamatus) iflavirus (PmIFV), denoted YB-PMP20, which was identified from the feces of $P$. mucrosquamatus (Crotalinae, Viperidae) through high-throughput sequencing. Sequence and phylogenetic analyses indicated that YBPMP20 showed high sequence identity with Hubei picorna-like virus 36 (HUPV 36) and Vespa velutina associated ifla-like virus (VVIAV), which were isolated from insects and closely clustered with iflavirus. This sequence analysis may contribute to understanding the evolution of iflavirus in snakes.

\section{Materials And Methods}

\subsection{Sample collection}

From July to September 2020, we collected seven anal swabs from brown-spotted pitvipers with lassos from quebrada and bamboo forests located in the Laojun mountains, 110 kilometers from Yibin city in Sichuan province (Fig. 1). To prevent sample contamination, we placed the animals individually in sterilized tubs and cleaned their skins with $75 \%$ alcohol. All samples were collected opportunistically with sterilized swabs in areas where pitvipers were captured. The swabs were placed in RNase-free tubes and immediately transported on dry ice to Shanghai Biozeron Biothchnology Co., Ltd. (Shanghai, China.) the same day. The pitvipers were then released back into the wild.

\subsection{RNA extraction}

Total RNA was extracted from tissue with TRIzol® Reagent according to the manufacturer's instructions (Invitrogen), and genomic DNA was removed with DNase I (TaKara). Then RNA quality was determined with a 2100 Bioanalyzer (Agilent) and quantified with an ND-2000 spectrophotometer (NanoDrop Technologies). High-quality RNA samples $\left(\mathrm{OD}_{260 / 280}=1.8-2.2, \mathrm{OD}_{260 / 230} \geq 2.0, \mathrm{RIN} \geq 6.5,28 \mathrm{~S}: 18 \mathrm{~S} \geq 1.0,>10 \mu \mathrm{g}\right)$ were used for sequencing library construction.

\subsection{Library preparation and Illumina HiSeq sequencing}

Metatranscriptome libraries were prepared with a TruSeq ${ }^{\text {TM }}$ Stranded Total RNA Sample Preparation Kit from Illumina (San Diego, CA), using $5 \mu \mathrm{g}$ of total RNA. Subsequently, rRNA removal was performed with Ribo-Zero ${ }^{\mathrm{TM}}$ rRNA Removal Kits from Illumina (San Diego, CA), and fragmentation was performed with fragmentation buffer. cDNA synthesis, end repair, A-base addition and ligation of the Illumina-indexed adaptors were performed according to Illumina's protocol. Libraries were then size selected for CDNA target fragments of 200-300 bp on 2\% Low Range Ultra Agarose and then amplified with PCR using Phusion DNA polymerase (NEB) for 15 PCR cycles. Metatranscriptomic sequencing was performed by Shanghai Biozeron Biothchnology Co., Ltd. (Shanghai, China) on an Illumina Novaseq 6000 instrument. All samples were sequenced on the lllumina HiSeq 2500 instrument. Libraries were prepared with a fragment length of approximately $450 \mathrm{bp}$. Paired-end reads were generated with $150 \mathrm{bp}$ in the forward and reverse directions.

\subsection{Read quality control and mapping}

The raw paired end reads were trimmed and subjected to quality control in Trimmomatic with parameters (SLIDINGWINDOW:4:15 MINLEN:75) (version 0.36 http://www.usadellab.org/cms/uploads/supplementary/Trimmomatic). Then, clean reads that aligned to the host genome were also removed. This set of high-quality reads was then used for further analysis. A total of 10.0 gigabases (Gb) of paired-end reads was obtained for the sample.

\subsection{Metatranscriptome assembly}


The clean reads were aligned to the SILVA SSU (16S/18S) and SILVA LSU (23S/28S) databases to remove rRNA related reads in SortMeRNA (http://bioinfo.lifl.fr/RNA/sortmerna/) software. Then, clean data from all samples were used for assembly with megahit (http://www.l3-

bioinfo.com/products/megahit.html).

All genes were predicted by METAProdigal (http://compbio.ornl.gov/prodigal/). Then, a non-redundant gene catalog was constructed with $95 \%$ identity and 90\% coverage by CD-HIT (http://www.bioinformatics.org/cd-hit/).

\subsection{Identification of the genome}

Reverse transcription of $1 \mu \mathrm{g}$ RNA from feces was conducted with random primers according to the manufacturer's protocol (TAKARA). Twelve pairs of primers were developed for PCR amplification, as previously described [27].

\subsection{Sequence alignment and phylogenetic analysis}

Sequence data were assembled and analyzed in Clustal X software and DNASTAR. To determine the relationship between the iflavirus representative isolates and YB-PMP20 strain, phylogenetic trees based on the whole gene sequence were constructed in molecular evolutionary genetics analysis (MEGA) software (version 6.0) with the maximum-likelihood method. Bootstrap values were estimated for 1,000 replicates. The sequences obtained in this study were assembled and submitted to GenBank under the accession number MZ005704.

\section{Results}

The genome of YB-PMP20 was 9808 nucleotides (nt) in length, with a nucleotide composition of 2827, 2329, 2680 and 1972, A, G, T and C nucleotides, respectively. The G + C content of the YB-PMP20 genome was $43.85 \%$ higher than that of other iflaviruses, including VVAILV144 (35.71\%), Aedes Ifla-like virus (36.42\%), Culex picorna-like virus 1 (36.75\%), Fitzroy Crossing iflavirus 1 (37.83\%), Darwin bee virus 2 (36.39\%) and Sanxia water strider virus 8 (37.06\%), and was lower than that of Lylv-1 (46.15\%). The genome has a 5 -untranslated region (UTR) followed by a single open reading frame spanning 8988 nt from position 304 to 9291, and a 3'-UTR region. A consensus invertebrate initiation sequence (ANNAUGG; N = any nucleotide) is located in nucleotide position 301$307 \mathrm{nt}$, and a translation initiation codon (AUG) is present at nucleotide position 304-306 nt. The polyprotein of 2995 amino acids has a calculated molecular mass of $335.3 \mathrm{kDa}$, an isoelectric point of 6.709 and a charge of -8.611 at $\mathrm{pH} 7$.

Alignment of the polyprotein sequences of YB-PMP20 and iflavirus showed the highest sequence identity with the HUPV 36 (99.2\% in nt and $99.6 \%$ in aa), LyIV-1 (46.6\% in nt and $20.9 \%$ in aa), VVILV (58.6\% in nt and $48.6 \%$ in aa) and AEIV (43.7\% in nt and $24.6 \%$ in aa) sequences.

The peptide domains of capsid proteins, helicase, peptidase and RNA directed RNA polymerase (RdRp) of YB-PMP20 were identified through similarity searches with the Simple Modular Architecture Research Tool (SMART: http://smart.embl-heidelberg.de), Conserved Domain Database (CDD:

http://www.ncbi.nlm.nih.gov/Structure/cdd/cdd/shtml) and SWISS-MODELbioinformatics server [28, 29]. YB-PMP20 polyprotein amino acid regions 130-382, 429-680 and 747-992 were identified as capsid proteins (VP) 2, 3 and 1, which shared lower protein sequence identities (30\%) with the sacbrood virus. However, the deduced VP4 was not found in the consensus sequences. RNA helicase domains were identified in the polyprotein from 1437-1583 aa, and showed $25.93 \%$ amino acid identity with 2 C helicase from enterovirus 71 (EV71) and 2C ATPase of picornavirus. Three conserved helicase motifs (A, B and C) are present in the picornavirus and iflavirus [30]. The highly conserved amino acids within motif A (GxxGxxGKS) and motif B (QxxxxxDD) were identified in the YB-PMP20 sequence, between amino acids 1449-1456 and 1495-1503. In YB-PMP20, the amino acids within motif C were KKxxxxPxxxxxATN, in contrast to the consensus motif, KGxxxxSxxxxxSTN. Proteases were identified from aa $2174-2379$ and showed $22.29 \%$ amino acid identity with $3 \mathrm{C}$ protease from coxsackievirus. The putative residues $\mathrm{H}^{2217}, \mathrm{E}^{2290}$ and $\mathrm{C}^{2340}$ may form the catalytic triad in the protease. RdRp domains were identified in aa $2416-2974$, and showed $20.86 \%$ amino acid identity with RdRp of sapporovirus. Eight conserved RdRp amino acid motifs are found in RNA viruses [30]. The putative RdRp conserved domains are shown in Fig. 3C. Furthermore, we constructed phylogenetic trees based on the full sequences, by using the maximum likelihood method. The iflaviruses clustered in a large clade, and two subclades were present. The phylogenetic trees indicated that YB-PMP20 clustered in the same subclade with HUPV 36, LyIV-1 and VVILV.

\section{Discussion}

In present study, we first identified and characterized an iflavirus strain (YB-PMP20) from brown-spotted pitvipers without apparent clinical symptoms, which shows characteristics typical of the family Iflaviridae, including the capsid protein, helicase, protease and RdRp domains. Sequence analysis suggested that YB-PMP20 is similar to HUPV 36, LyIV-1 and VVAIV, identified in Diptera, Lygus lineolaris and Vespa velutina nigrithorax, respectively.

Metagenomic studies of invertebrate viruses have recently been undertaken. More than 220 invertebrate species, including 9 metazoan phyla, were identified at least 1,445 distinct virus genomes segments [31]. It indicated that invertebrates acted as viral vectors, could play a key role in transmit and reservoir of pathogens.

Snakes may be a common predator of monkeys [32], shell snails [33], kangaroos [33], fishes [33], leeches [33], earthworms [33], frogs [33], tadpoles [33], fish eggs [34], lizards [35, 36], field voles [36] and shrews [36]. There are no reports to support the idea that snakes prey on insects. We speculated that 1) snakes may occasionally prey on insects, thus, resulting in transmission of the virus from insects to snakes; 2) generally, amphibians including frogs feed on insects, thus, resulting in pathogen transmission from insects to amphibians. Then, snakes preying on amphibians might become a reservoir of insect and amphibian pathogens. To investigate the epidemiology of iflavirus in snakes, a large-scale survey is needed. Such an investigation would aid in understanding the prevalence of iflavirus and across the range of all snake species. 


\section{Conclusion}

We first identified and characterized an iflavirus strain (YB-PMP20) from brown-spotted pitvipers. Phylogenetic analysis indicated that YB-PMP20 belongs to the iflavirus cluster, and is similar to HUPV, LyIV-1 and VVAIV. These findings contribute to our understanding of the prevalence of viruses in snake species.

\section{Abbreviations}

Hubei picorna-like virus (HUPV), Vespa velutina-associated iflavirus like virus (VVAIV), Lygus lineolaris virus (LyIV-1), gigabases (Gb), molecular evolutionary genetics analysis (MEGA), RNA directed RNA polymerase (RdRp), enterovirus 71 (EV71).

\section{Declarations}

\section{Ethics approval and consent to participate}

The present study was approved by the Animal Ethics Committee of Yibin University, Yibin, China, according to the OIE standards for use of animals in research and education.

\section{Consent for publication}

Not applicable.

\section{Availability of data and materials}

The complete sequences obtained in this study have been submitted to the GenBank database (accession number: MZ005704)

\section{Competing interests}

The authors declare no competing interests.

Author Contributions: Conceptualization, HXL, GP; methodology, TZG., DY, CHZ; formal analysis, TZG, HXL, GP; investigation, DY, ZMM, TT, JFR, ZAT, CHZ, LY; resources, DY, ZMM, TT, JFR, ZAT and XX; writing original draft preparation, TZG; writing review and editing, TZG, GP; supervision, HXL, GP; project administration, $\mathrm{HXL}$; funding acquisition, $\mathrm{HXL}, \mathrm{GP}$.

Funding: This work was supported by the Doctor Launch Project of Yibin University (No. 2019QD09 and No. 2019QD10), and the Second Tibetan Plateau Scientific Expedition and Research (STEP) program (2019QZKK05010105) and Sciences and Technology Department of Sichuan Province (2020YFSY0033).

Conflicts of Interest: The authors declare no conflicts of interest.

\section{References}

1. Valles SM, Chen Y, Firth AE, Guérin DMA, Hashimoto Y, Herrero S, de Miranda JR, Ryabov E, Ictv Report C: ICTV Virus Taxonomy Profile: Iflaviridae. The Journal of general virology 2017, 98(4):527-528.

2. Ghosh RC, Ball BV, Willcocks MM, Carter MJ: The nucleotide sequence of sacbrood virus of the honey bee: an insect picoma-like virus. The Journal of general virology 1999, 80 (Pt 6):1541-1549.

3. Choe SE, Nguyen LT, Noh JH, Kweon CH, Reddy KE, Koh HB, Chang KY, Kang SW: Analysis of the complete genome sequence of two Korean sacbrood viruses in the Honey bee, Apis mellifera. Virology 2012, 432(1):155-161.

4. Wu N, Zhang P, Liu W, Cao M, Massart S, Wang X: Complete genome sequence and characterization of a new iflavirus from the small brown planthopper (Laodelphax striatellus). Virus research 2019, 272:197651.

5. Thekke-Veetil T, Lagos-Kutz D: Soybean Thrips (Thysanoptera: Thripidae) Harbor Highly Diverse Populations of Arthropod, Fungal and Plant Viruses. 2020, 12(12).

6. Ongus JR, Peters D, Bonmatin JM, Bengsch E, Vlak JM, van Oers MM: Complete sequence of a picorna-like virus of the genus Iflavirus replicating in the mite Varroa destructor. The Journal of general virology 2004, 85(Pt 12):3747-3755.

7. Kubacki J, Flacio E, Qi W, Guidi V: Viral Metagenomic Analysis of Aedes albopictus Mosquitos from Southern Switzerland. 2020, 12(9).

8. Cholleti H, Hayer J, Fafetine J, Berg M, Blomström AL: Genetic characterization of a novel picorna-like virus in Culex spp. mosquitoes from Mozambique. Virology journal 2018, 15(1):71.

9. Wu N, Zhang P, Liu W, Cao M, Wang X: Sequence analysis and genomic organization of a new insect iflavirus, Sogatella furcifera honeydew virus 1 . 2018, 163(7):2001-2003.

10. Wang H, Liu Y, Liu W, Cao M, Wang X: Full genome sequence of a novel iflavirus from the leafhopper Psammotettix alienus. 2019, 164(1):309-311.

11. Hyatt AD, Williamson M, Coupar BE, Middleton D, Hengstberger SG, Gould AR, Selleck P, Wise TG, Kattenbelt J, Cunningham AA et al: First identification of a ranavirus from green pythons (Chondropython viridis). Journal of wildlife diseases 2002, 38(2):239-252.

12. Wellehan JF, Jr., Strik NI, Stacy BA, Childress AL, Jacobson ER, Telford SR, Jr.: Characterization of an erythrocytic virus in the family Iridoviridae from a peninsula ribbon snake (Thamnophis sauritus sackenii). Veterinary microbiology 2008, 131(1-2):115-122.

13. Hauser B, Mettler F, Rübel A: Herpesvirus-like infection in two young boas. Journal of comparative pathology 1983, 93(4):515-519. 
14. Ogawa M, Ahne W, Essbauer S: Reptilian viruses: adenovirus-like agent isolated from royal python (Python regius). Zentralblatt fur Veterinarmedizin Reihe B Journal of veterinary medicine Series B 1992, 39(10):732-736.

15. Juhasz A, Ahne W: Physicochemical properties and cytopathogenicity of an adenovirus-like agent isolated from corn snake (Elaphe guttata). Archives of virology 1993, 130(3-4):429-439.

16. Ahne W, Scheinert P: Reptilian viruses: isolation of parvovirus-like particles from corn snake Elapha guttata (Colubridae). Zentralblatt fur Veterinarmedizin Reihe B Journal of veterinary medicine Series B 1989, 36(6):409-412.

17. Altan E, Kubiski SV, Burchell J, Bicknese E, Deng X, Delwart E: The first reptilian circovirus identified infects gut and liver tissues of black-headed pythons. Veterinary research 2019, 50(1):35.

18. Zeigel RF, Clark HF: Electron microscopic observations on a "C"-type virus in cell cultures derived from a tumor-bearing viper. Journal of the National Cancer Institute 1969, 43(5):1097-1102.

19. Ahne W, Thomsen I, Winton J: Isolation of a reovirus from the snake, Python regius. Brief report. Archives of virology 1987, 94(1-2):135-139.

20. Fölsch DW, Leloup P: [Fatal endemic infection in a serpentarium. Diagnosis, treatment and preventive measures]. Tierarztliche Praxis 1976, 4(4):527-536.

21. Essbauer S, Ahne W: Viruses of lower vertebrates. Journal of veterinary medicine B, Infectious diseases and veterinary public health 2001, 48(6):403-475.

22. Kolesnikovas CK, Grego KF, Rameh de Albuquerque LC, Jacobson ER, Monezi TA, Mehnert DU, Catão-Dias JL: Ophidian paramyxovirus in Brazilian vipers (Bothrops alternatus). The Veterinary record 2006, 159(12):390-392.

23. Smith AW, Anderson MP, Skilling DE, Barlough JE, Ensley PK: First isolation of calicivirus from reptiles and amphibians. American journal of veterinary research 1986, 47(8):1718-1721.

24. Lee HW, Min, B.W., Lim, Y.W: Isolation and serologic studies of Japanese encephalitis virus from snakes in Korea. J Korean Med Assoc 1972, 15:69-74.

25. Burton AN, McLintock J, Rempel JG: Westem equine encephalitis virus in Saskatchewan garter snakes and leopard frogs. Science (New York, NY) 1966, 154(3752):1029-1031.

26. Heldstab A, Bestetti G: Virus associated gastrointestinal diseases in snakes. The Journal of Zoo Animal Medicine 1984, 15(3):118-128.

27. Hu X, Jr., Li N, Jr., Tian Z, Jr., Yin X, Jr., Qu L, Qu J: Molecular characterization and phylogenetic analysis of transmissible gastroenteritis virus HX strain isolated from China. BMC veterinary research 2015, 11:72.

28. Arnold K, Bordoli L, Kopp J, Schwede T: The SWISS-MODEL workspace: a web-based environment for protein structure homology modelling. Bioinformatics (Oxford, England) 2006, 22(2):195-201.

29. Kiefer F, Arnold K, Künzli M, Bordoli L, Schwede T: The SWISS-MODEL Repository and associated resources. Nucleic acids research 2009, 37(Database issue):D387-392.

30. Koonin EV, Dolja VV: Evolution and taxonomy of positive-strand RNA viruses: implications of comparative analysis of amino acid sequences. Critical reviews in biochemistry and molecular biology 1993, 28(5):375-430.

31. Shi M, Lin XD, Tian JH, Chen LJ, Chen X, Li CX, Qin XC, Li J, Cao JP, Eden JS et al: Redefining the invertebrate RNA virosphere. Nature 2016, 540(7634):539-543.

32. Quintino EP, Bicca-Marques JC: Predation of Alouatta puruensis by Boa constrictor. Primates; journal of primatology 2013, 54(4):325-330.

33. Danaisawadi P, Asami T, Ota H, Sutcharit C, Panha S: A snail-eating snake recognizes prey handedness. Scientific reports $2016,6: 23832$.

34. Li M, Fry BG, Kini RM: Eggs-only diet: its implications for the toxin profile changes and ecology of the marbled sea snake (Aipysurus eydouxii). Journal of molecular evolution 2005, 60(1):81-89.

35. Durso AM, Mullin SJ: Ontogenetic shifts in the diet of plains hog-nosed snakes (Heterodon nasicus) revealed by stable isotope analysis. Zoology (Jena, Germany) 2017, 120:83-91.

36. Brown DS, Ebenezer KL, Symondson WO: Molecular analysis of the diets of snakes: changes in prey exploitation during development of the rare smooth snake Coronella austriaca. Molecular ecology 2014, 23(15):3734-3743.

\section{Tables}


Table 1

Primers used for identifying and sequencing the YB-

\begin{tabular}{|c|c|c|}
\hline Name & Sequence $\left(5^{\prime}-3^{\prime}\right)$ & Position \\
\hline $1 \mathrm{~F}$ & TTCTTACCCCAAAGGTAGGA & $1-20$ \\
\hline $1 \mathrm{R}$ & CAACCAGCTTAAATTCTACA & $990-1009$ \\
\hline $2 \mathrm{~F}$ & СTTTTCATTGAGGATCCCAG & $900-919$ \\
\hline $2 \mathrm{R}$ & СTTAACAATGTCAAACTCAT & 1970-1989 \\
\hline $3 F$ & TGATATTGCTAAGAAGCAGA & $1800-1819$ \\
\hline $3 R$ & ATTTTTTGGTCGAATAAGTT & $2870-2889$ \\
\hline $4 \mathrm{~F}$ & CAGCACCAAATAACTAAGAT & $2746-2765$ \\
\hline $4 \mathrm{R}$ & АCTTCACCCAGATCTGTCAA & $3727-3746$ \\
\hline $5 F$ & GCATACGATCTATGATCTTA & $3471-3490$ \\
\hline $5 \mathrm{R}$ & ATTCCTAACGAACAAGAAAG & $4268-4287$ \\
\hline $6 \mathrm{~F}$ & TTGGCAAAATACTTAAGCAG & $4034-4053$ \\
\hline $6 \mathrm{R}$ & TTAACTAAGACGTCTCGTCT & $5014-5033$ \\
\hline $7 F$ & CTGAGCTCTACCAGCTGAAG & $4856-4875$ \\
\hline 7R & AACAAGCTCATAATTACAAC & $5842-5861$ \\
\hline $8 \mathrm{~F}$ & TGTAGCAAAATCTCCTGTGG & $5677-5696$ \\
\hline $8 \mathrm{R}$ & ATATCGCTGTAGTTTTCAGC & $6514-6533$ \\
\hline $9 \mathrm{~F}$ & GCCTTGTAACACTACTGATT & $6387-6406$ \\
\hline $9 \mathrm{R}$ & GCTCTAATTCTAGCTCCAGT & $7405-7424$ \\
\hline $10 \mathrm{~F}$ & TAGTGCATATGATGAACTGA & $7242-7261$ \\
\hline $10 \mathrm{R}$ & AGCGAAGGTGAGAAGTAAAA & $8205-8224$ \\
\hline $11 \mathrm{~F}$ & GGAGGCAAGGAATTTTAGCA & $8054-8073$ \\
\hline $11 \mathrm{R}$ & CATATGATAGCAATAGGCTA & $9081-9100$ \\
\hline $12 \mathrm{~F}$ & TCTCCAAAACATGTCATTTT & $8922-8941$ \\
\hline $12 \mathrm{R}$ & TTTATATTGTTTTTGTATTT & $9789-9808$ \\
\hline
\end{tabular}

Table 2

Comparison of amino acid and nucleotide sequence identity between YB-PMP20 and other representative Iflaviruses

\begin{tabular}{|c|c|c|c|c|c|c|c|c|c|c|c|c|c|c|c|c|c|c|c|}
\hline & \multicolumn{2}{|c|}{ YB-PMP20 } & \multicolumn{2}{|l|}{ WIV } & \multicolumn{2}{|l|}{ AEIV } & \multicolumn{2}{|c|}{ CUPV1 } & \multicolumn{2}{|c|}{ DABV } & \multicolumn{2}{|c|}{ FCIV1 } & \multicolumn{2}{|c|}{ HUPV36 } & \multicolumn{2}{|l|}{ LyIV1 } & \multicolumn{2}{|l|}{ REBV } & \multirow{2}{*}{$\frac{\mathrm{S}}{\mathrm{n}}$} \\
\hline & $\mathrm{nt} \%$ & $a a \%$ & $\mathrm{nt} \%$ & $a a \%$ & nt\% & $a a \%$ & $\mathrm{nt} \%$ & $a a \%$ & $\mathrm{nt} \%$ & $a a \%$ & $\mathrm{nt} \%$ & $a a \%$ & nt\% & $a a \%$ & nt\% & $a a \%$ & nt\% & $a a \%$ & \\
\hline Polyprotein & 100 & 100 & 58.6 & 48.6 & 43.7 & 24.6 & 44.1 & 24.5 & 37.1 & 22.7 & 36.8 & & 99.2 & 99.6 & 46.6 & 20.9 & 36.8 & 22.9 & 3 \\
\hline VP1 & 100 & 100 & 62.6 & 56.4 & 42 & 27 & 42.4 & 26.2 & 29.1 & 31.2 & 32.9 & 28.4 & 99.2 & 98.8 & 47.5 & 29.7 & 30.5 & 27.9 & 31 \\
\hline VP2 & 100 & 100 & 64.3 & 65.2 & 40.1 & 25.7 & 41.4 & 25.7 & 35.4 & 20 & 31.6 & 17.4 & 99.5 & 99.6 & 49.3 & 21.2 & 34.3 & 21.9 & 3 \\
\hline VP3 & 100 & 100 & 64.1 & 64.3 & 43.1 & 28.5 & 43.3 & 28.1 & 36.3 & 26.8 & 38.6 & 29.6 & 99.3 & 100 & 46.1 & 29 & 36.4 & 26.8 & $3 !$ \\
\hline Helicase & 100 & 100 & 70.2 & 78.9 & 34.4 & 29.3 & 36.3 & 29.3 & 45.8 & 40.1 & 50.2 & 37.4 & 99.1 & 100 & 53.9 & 42.1 & 49.8 & 38.8 & 41 \\
\hline Protease & 100 & 100 & 58.6 & 50 & 47.4 & 25.6 & 46.9 & 25.6 & 40.6 & 22.8 & 38.1 & 22.9 & 99.5 & 100 & 50.5 & 27 & 37.6 & 22.9 & 3 \\
\hline $\mathrm{RdRp}$ & 100 & 100 & 58.6 & 56.5 & 47.4 & 40.1 & 46.9 & 40.5 & 40.6 & 36.1 & 38.1 & 32.9 & 99.5 & 99.8 & 45.3 & 33.2 & 37.6 & 34.3 & 3 \\
\hline
\end{tabular}

\section{Figures}




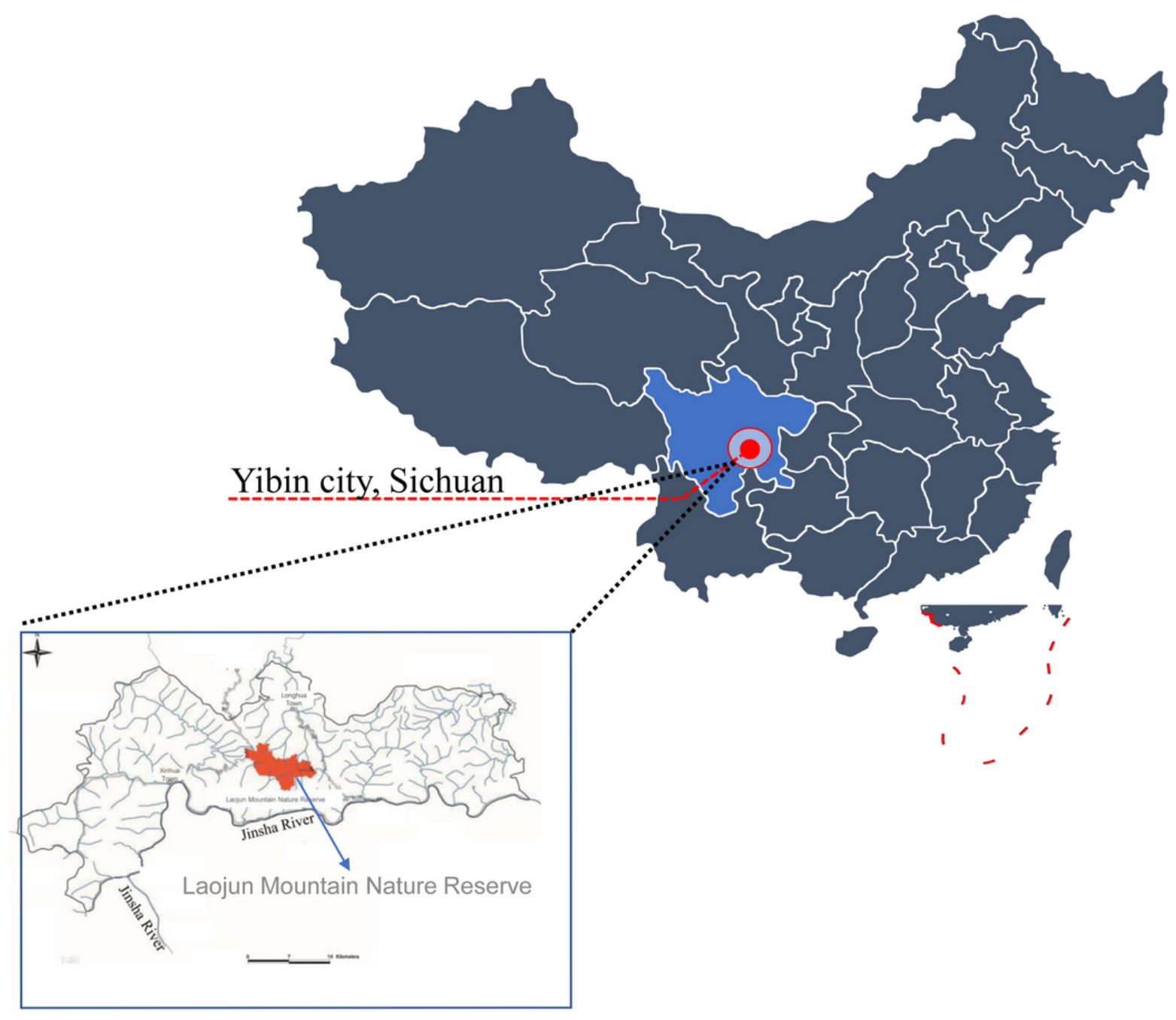

Figure 1

Map of Laojun Mountain Nature Reserve. 
A

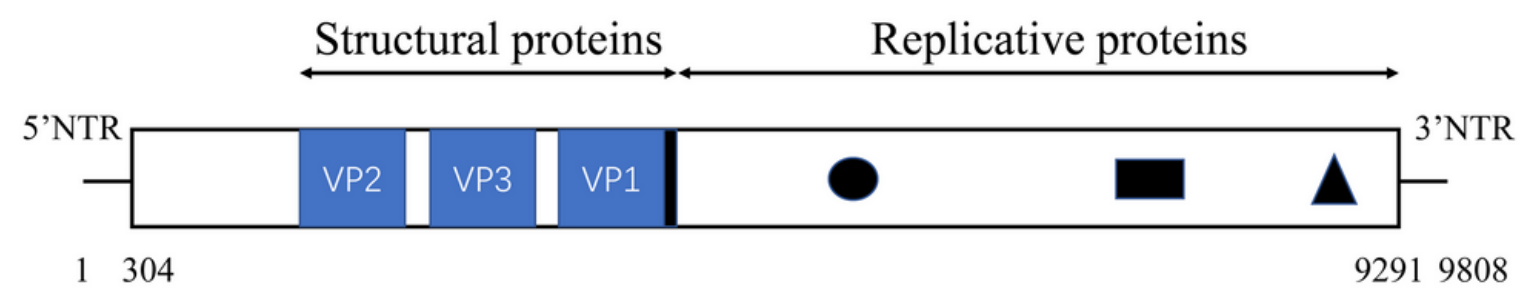

B

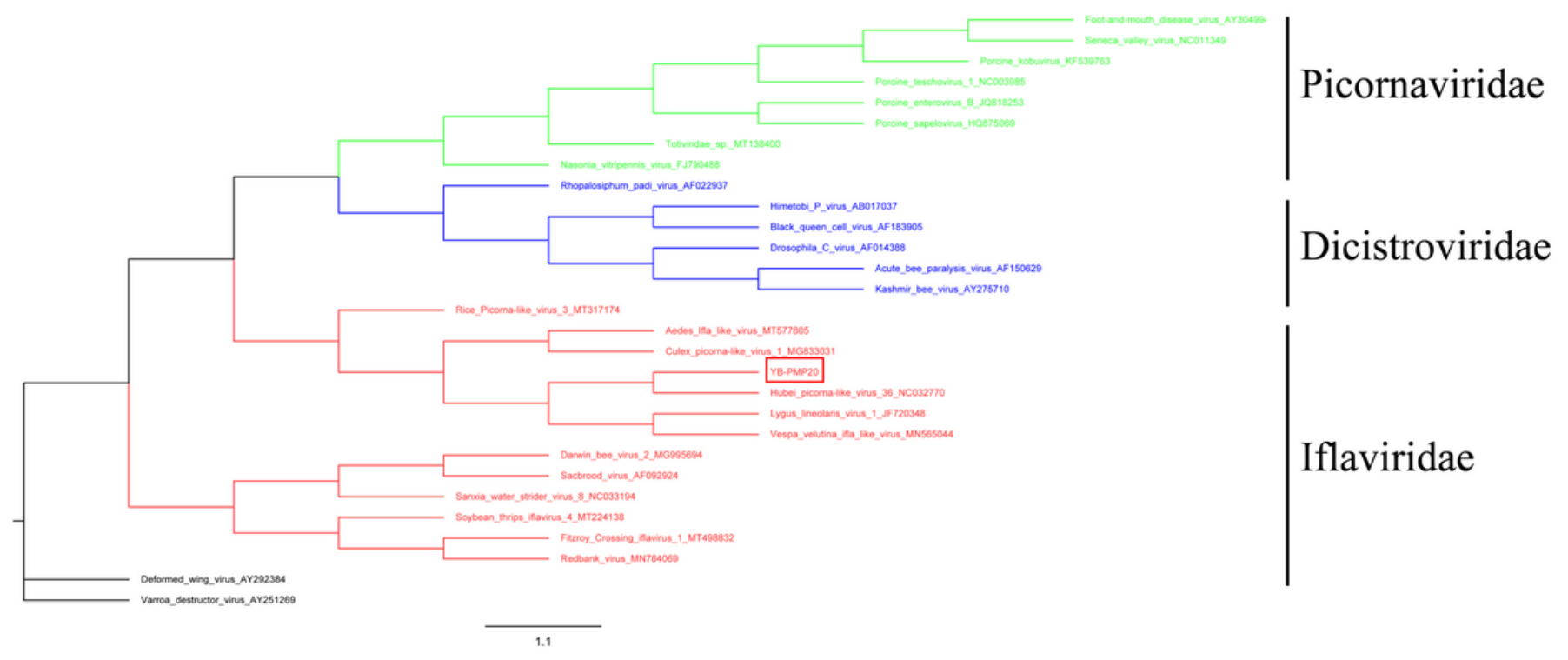

Figure 2

Please see the Manuscript file for the complete figure caption. 
A

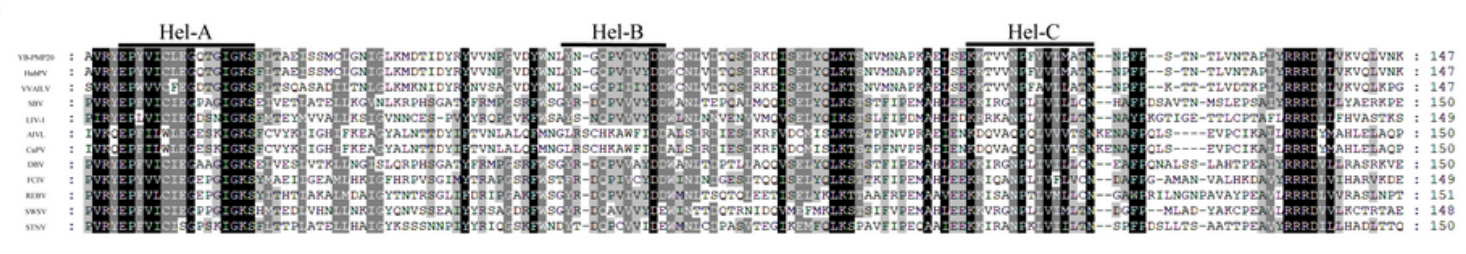

B

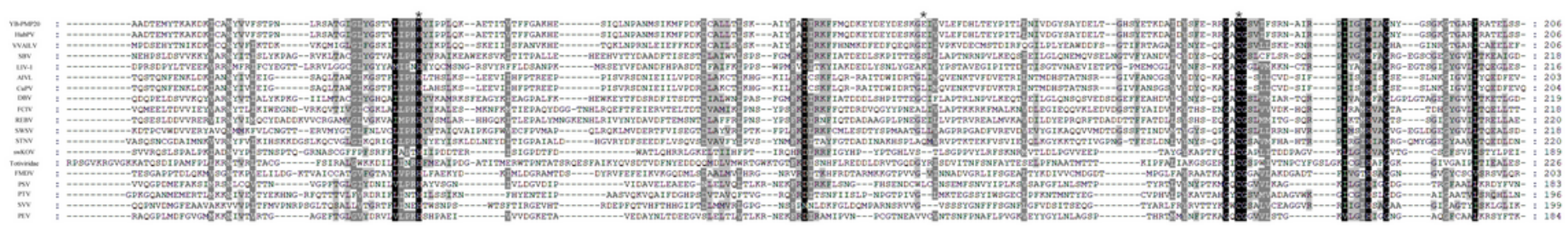

C

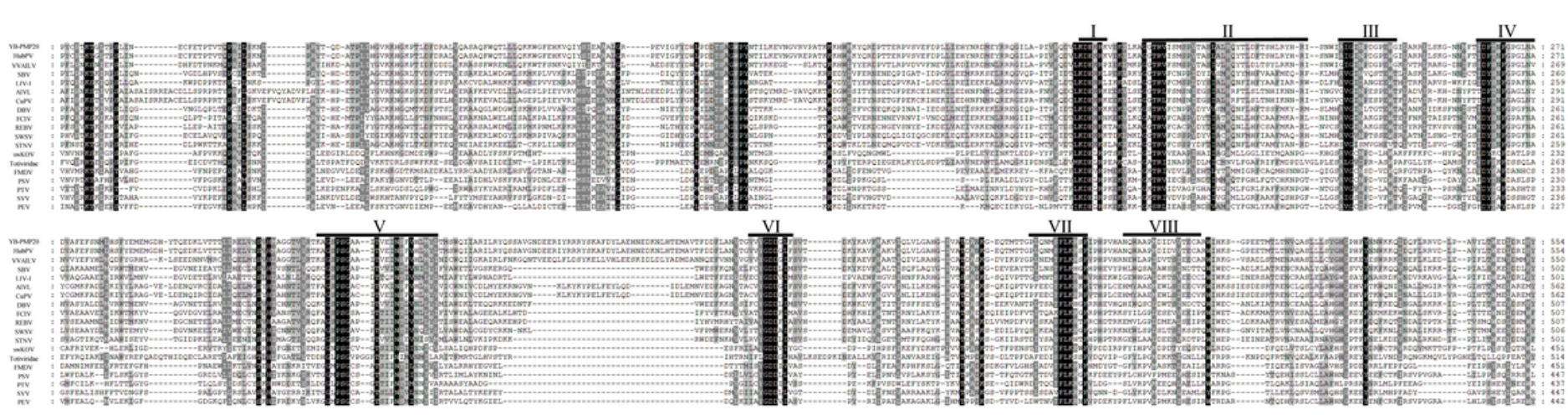

Figure 3

Alignment of the conserved amino acid motifs of the Helicase (A), Protease (B) and RdRp (C). 